Available online at www.iponlinejournal.com

\title{
Awareness and knowledge of Diabetic retinopathy among Diabetic patients in a tertiary care hospital of western Odisha, India
}

\author{
Ravindra Kumar Chowdhury ${ }^{1 *}$, Jayashree Dora ${ }^{2}$, Kshyanaprava Priyadarshini ${ }^{3}$ \\ ${ }^{\mathbf{1}}$ Assistant Professor, ${ }^{2}$ Professor, ${ }^{3} \mathrm{PG}$ Resident, ${ }^{\mathbf{1 - 3}}$ Dept. of Ophthalmology, ${ }^{\mathbf{1 - 3}}$ Veer Surendra Sai Institute of Medical Science and Research, \\ Burla, Odisha, India
}

\section{Article Info}

Received: $4^{\text {th }}$ February, 2019

Accepted: $6^{\text {th }}$ May, 2019

Published Online: $9^{\text {th }}$ September, 2019

Keywords: Awareness, Diabetic retinopathy, Knowledge, Practice.

\begin{abstract}
Aim: To evaluate the knowledge and awareness of diabetic retinopathy among diabetic patients.

Materials and Methods: We conducted a cross-sectional study on the occasion of world diabetes day. A pretested semi-structured questionnaire (21 points with 16 questions) was prepared and distributed among the diabetic population visiting the camp. The questionnaire was mainly prepared to assess the knowledge, awareness, and practice of diabetic retinopathy. Result: 192 diabetic patients attending the camps were included in our study. Male to female ratio of the diabetic population was found to be $3: 1$. The awareness about the complication of diabetic retinopathy was higher among 51 to 60 years of age group with a p-value of 0.0145 . Out of the total study population, $32.4 \%$ belonged to the knowledge group with the right attitude. $31.25 \%$ had knowledge about diabetes \& its complications and $47.9 \%$ had a practice of going for a routine eye checkup.

Conclusion: The knowledge of diabetic retinopathy can be improved in a population by increasing the awareness about diabetic retinopathy. Such an awareness campaign on world diabetic day can help in early detection and timely intervention of diabetes. The rates of diabetic retinopathy related blindness can be controlled by increasing awareness about it.
\end{abstract}

\section{Introduction}

Diabetes mellitus (DM) is a metabolic disease where the body cannot regulate the amount of glucose in the blood. ${ }^{1}$ In both developed and developing countries, the prevalence of diabetes mellitus (DM) is increasing. By the year 2025, the numbers of patients with DM will double making it a major public health problem. ${ }^{2-4}$

Further DM is a leading cause of blindness worldwide due to its ocular complications. ${ }^{5}$ It is estimated that diabetic retinopathy (DR) constitutes $4.8 \%$ of the global causes of blindness. ${ }^{6}$ In India, the prevalence of blindness due to diabetic retinopathy ranges from $7.3 \%$ to $25 \%{ }^{7-12}$ The patients with poor glycemic control have a higher risk for $\mathrm{DR}^{13}$ The duration of $\mathrm{DM}$ in a patient is an another important factor in developing DR. It has been observed that more than $77 \%$ of patients who survive for over 20 years with diabetes are affected with retinopathy. ${ }^{14}$ DR has been included in the disease-control strategy of the VISION 2020 initiative due to its significant impact on the causes of blindness. ${ }^{15,16}$ This disease remains usually undetected owing to the silent nature, Hence, early screening remains a mainstay weapon of control. Diabetic retinopathy is the most common microvascular ocular complication of DM. The risk factors for DR includes uncontrolled maintenance of blood sugar, longer duration of DM and the presence of other associated systemic disorders. ${ }^{17}$

The possible visual impairment due to DR can be halted by increasing the level of awareness. ${ }^{18}$ This the study was conducted to assess the knowledge and attitude of the diabetic population regarding diabetic retinopathy on the occasion of world diabetic day.

\section{Materials and Methods}

This cross-sectional study was conducted at a health campaign on the occasion of World Diabetes Day. A pretested semistructured questionnaire (21point with 16 questions) was prepared and distributed among the diabetic population visiting the camp. Participants were asked to answer questions which included questions about awareness $\&$ the knowledge of DR and practice related to it.

The questionnaire consisted of 2 parts. The first part contained the demographic profile, details of diabetes like duration, family history, any ocular complaints. The second part consisted of questions based on knowledge, attitude \& practice of diabetes patients regarding the complication of diabetic retinopathy. Statistical analysis was performed using SPSS v 22 software.

The questions which assessed the knowledge of diabetic patients were recorded either as yes, no or don't

\footnotetext{
*Corresponding Author: Ravindra Kumar Chowdhury, Assistant Professor, Dept. of Ophthalmology, Veer Surendra Sai Institute of Medical Science and Research, Burla, Odisha, India

Email: ravindrachowdhury@gmail.com

http://doi.org/10.18231/j.ijceo.2019.070
} 
know. Based on the response given by the patients, they were grouped as knowledge group (those who have given a positive response) \& non-knowledge group (those who have given a negative response). The association of knowledge of diabetic retinopathy with attitude \& practices was evaluated using the chi-square test. A p-value of $<0.05$ was taken to be statistically significant.
The patients with type -2 DM with age more than 40 years were included in our study. The patients with type 1 DM and age less than 40 years were excluded. Informed consent was obtained from all individual patients who were included in the study.
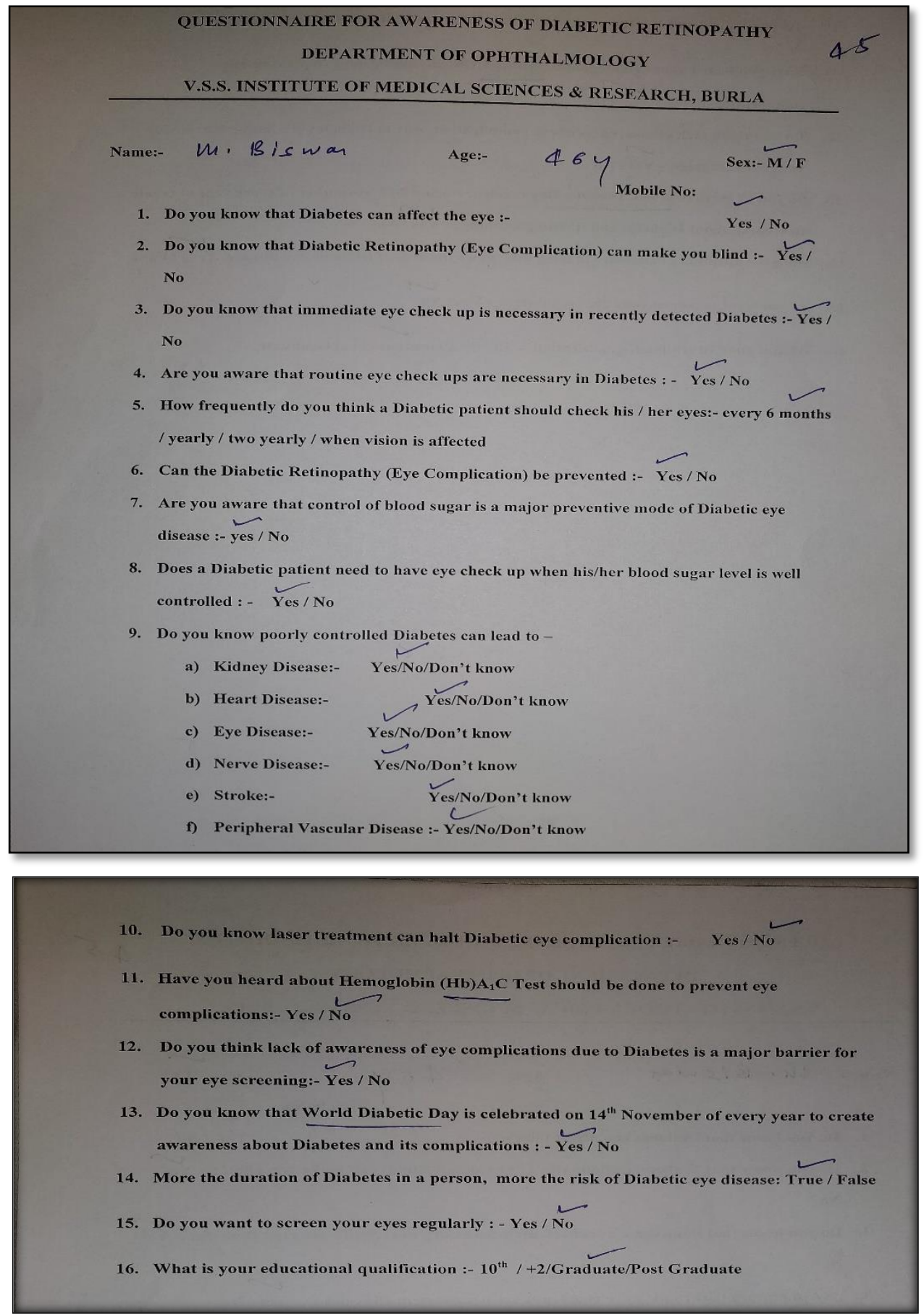

Fig. 1: Questionnaire on awareness of diabetic retinopathy 


\section{Results}

192 diabetic patients participated in the present study. The number of males and females being $144(75 \%)$ and $48(25 \%)$ respectively. The average age of patients was found to be $55.5 \mathrm{yrs}$ and $43.75 \%$ belonged to the age group of 51-60yrs. [Table 1] So far educational background is concerned, $49.4 \%$ had completed their graduation. The duration of DM was less than 10 years in 148 patients $(77.1 \%)$. Age and educational status of patients affected the awareness status of diabetic retinopathy in our study. The association of age and educational qualification with the awareness of diabetic retinopathy was depicted in table 2 and table 3.

Table 1: Demographic Profile

\begin{tabular}{|c|c|c|}
\hline Age(years) & $41-50$ & $44(22.92 \%)$ \\
\hline & $51-60$ & $84(43.75 \%)$ \\
\hline & $61-70$ & $52(27.08 \%)$ \\
\hline & $71-80$ & $12(0.06 \%)$ \\
\hline Gender & Male & $144(75 \%)$ \\
\hline & Female & $48(25 \%)$ \\
\hline Educational Status & $10^{\text {th }}$ & $71(36.9 \%)$ \\
& Graduate & $95(49.4 \%)$ \\
& Postgraduate & $26(13.5 \%)$ \\
\hline Duration of Diabetes & Less than 10 years & $148(77.1 \%)$ \\
& $10-20$ years & $32(16.6 \%)$ \\
& More than 20 years & $12(6.25 \%)$ \\
\hline
\end{tabular}

Table 2: Age based awareness about diabetic retinopathy

\begin{tabular}{|c|c|c|c|c|}
\hline Age & Knowledge group & Non-knowledge Group & Total & p-value \\
\hline $41-50$ & 8 & 36 & 44 & \\
\hline $51-60$ & 24 & 60 & 84 & \\
\hline $61-70$ & 28 & 24 & 52 & 0.0145 \\
\hline $71-80$ & 0 & 12 & 12 & \\
\hline Total & 60 & 132 & 192 & \\
\hline
\end{tabular}

Table 3: Knowledge based on educational status

\begin{tabular}{|c|c|c|c|}
\hline Educational status & Knowledge group & Non-knowledge group & Percentage (total) \\
\hline $10^{\text {th }}$ & $18(25 \%)$ & $53(75 \%)$ & $36.9 \%$ \\
\hline Graduate & $71(74.7 \%)$ & $24(25.3 \%)$ & $49.4 \%$ \\
\hline Post-graduate & $20(90.9 \%)$ & $2(9.09 \%)$ & $11.4 \%$ \\
\hline
\end{tabular}

The knowledge, attitude, and practice of diabetic retinopathy in our study group were depicted in table $4.68 .75 \%$ had knowledge that diabetes can lead to microangiopathic complications and affect the eye. $54.1 \%$ knew that diabetes can make them blind if not treated properly. Necessity about immediate eye checkup was dismissed by most of the participants with only $31.25 \%$ giving emphasis to that. Routine eye checkup was considered to be important by $16.6 \%$ of patients. Longer the duration of diabetes higher the risk of ocular complications was known to $56.25 \%$ of the study population.

Table 4: Association of awareness about diabetic retinopathy

\begin{tabular}{|l|c|c|c|}
\hline & Yes & No & P Value \\
\hline Know that diabetes can affect the Eye & 132 & 60 & 0.501 \\
\hline know that diabetic retinopathy can make you blind & 104 & 88 & 0.422 \\
\hline know that immediate eye check-up is necessary for recently & $60(1)$ & $132(1)$ & $0.0145(1)$ \\
detected diabetes & Male-60 & Male-84 & $0.005(2)$ \\
& Female-0 & Female-48 & \\
\hline Awareness about routine eye checkup in diabetes & 32 & 160 & $0.045(1)$ \\
& Male-8 & Male-136 & $0.002(2) \mathrm{KN}$ \\
\hline risk of diabetic eye disease increases with duration & Female-24 & Female-24 & \\
\hline
\end{tabular}


Table 5

\begin{tabular}{|c|c|c|c|c|}
\hline & $\begin{array}{c}\text { Knowledge of } \\
\text { diabetic retinopathy }\end{array}$ & $\begin{array}{c}\text { Knowledge based } \\
\text { on educational status }\end{array}$ & $\begin{array}{c}\text { Knowledge group } \\
\text { with right attitude }\end{array}$ & $\begin{array}{c}\text { Practice of going } \\
\text { for eye checkup }\end{array}$ \\
\hline Our Study & $31.25: 68.75 \%(Y: N)$ & More with higher education & $32.4 \%$ & $47.9 \%$ \\
\hline Geethadevi et al & $39.19: 60.8 \%(Y: N)$ & More with Higher Education & $85.46 \%$ & $42.51 \%$ \\
\hline Hussain et al & $55.6: 44.4 \%(Y: N)$ & More with good literacy status & $75.3 \%$ & $57.6 \%$ \\
\hline Raghu V et al & $83: 17 \%(Y: N)$ & More with higher education & - & - \\
\hline
\end{tabular}

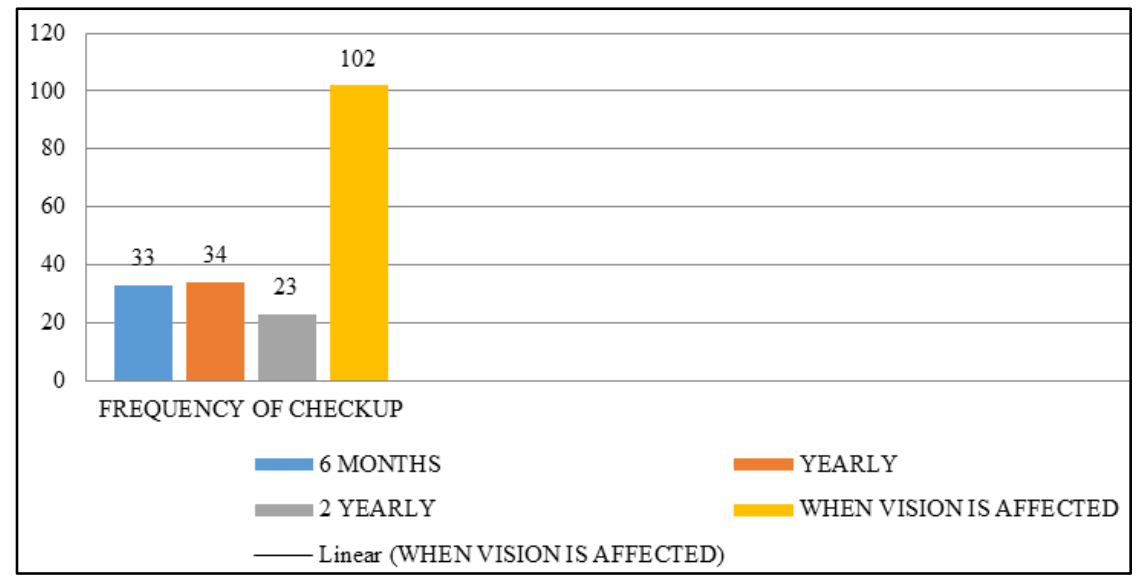

Fig. 2: Awareness of frequency of eye check in DR

$53.12 \%$ of diabetic patients considered that routine eye checkup is necessary only when vision is affected.17.1\% were aware that 6 monthly routine eye checkup is necessary for diabetes [Fig. 2]. 32.29\% were aware that even when blood sugar parameters were controlled, eye checkup should be done routinely. Systemic complications in poorly controlled diabetes were not known to most of the participants. $69 \%$ thought that lack of awareness was one of the key factors for the poor knowledge about manifestations of diabetes. $85.9 \%$ had knowledge of laser treatment as a modality to prevent diabetic eye complications.

\section{Discussion}

The lack of awareness about diabetic retinopathy in diabetic patients is considered as a major cause of diabetic blindness in our community. The main objective of this study was to ascertain the awareness level and the practice patterns adopted by diabetic patients in the community.

Our study revealed that $31.25 \%$ of the study population had knowledge about diabetic retinopathy, which was comparable to a study by Geethadevi et al. ${ }^{19}$ Knowledge about diabetic retinopathy was more among people with higher educational status. This highlights that educational status is an important factor for the knowledge \& awareness of diabetic retinopathy.

Our study was compared with other similar studies in a tabulated form (table 5)

Out of the knowledge group, only $32.4 \%$ had the right attitude towards the practice of healthy lifestyle \& the need for a regular routine eye checkup. Level of awareness was higher among those who had diabetes for a longer duration. $47.9 \%$ had the practice of going out for regular eye checkup, which was comparable to studies done by Hussain et al \&
Raghu et al..$^{20,21}$ The cause given by patients for not getting an early diabetic retinopathy screening was mainly a lack of information about diabetic eye complications.

Namperumalsamy et al. ${ }^{22}$ observed that fundoscopy was done by $6.8 \%$ of the patients with a history of diabetes mellitus in their project. Out of this, only one fourth screened diabetic retinopathy patients returned for regular examination in the hospitals. This highlights the fact that apart from good knowledge and attitude, motivation for evaluation $\&$ follow up also plays a significant role.

Out of 192 patients, 72(37.5\%) knew that diabetic eye complication can be prevented. 93(48.5\%) patients were aware that control of blood sugar is a major preventive mode of diabetic eye disease. Only 20(10.4\%) had an idea about laser treatment in diabetic eye disease

It is a very well known fact that diabetic retinopathy complications become more severe with prolonged duration of diabetes. So it is imperative to spread the awareness on diabetic retinopathy screening to diabetic patients. Early screening for diabetic retinopathy should be adopted by the practitioners at the early stages of diabetes mellitus. Furthermore, well-planned strategies need to follow for public health awareness campaigns.

\section{Conclusion}

Increasing knowledge about diabetic retinopathy through awareness campaigns can improve attitude \& practice. Early detection \& timely intervention can help in preventing sightthreatening complications.

Source of Funding: None.

Conflict of Interest: None. 


\section{References}

1. Olokoba AB, Obateru OA, Olokoba LB. Type 2 diabetes mellitus: a review of current trends. Oman Med $J$ 2012;27(4):269-73.

2. Rani P, Raman R, Subramani S, Knowledge of diabetes and diabetic retinopathy among rural populations in India, and the influence of knowledge of diabetic retinopathy on attitude and practice. Rural Remote Health 2008;8:838

3. Rathmann W, Giani G. Global prevalence of diabetes: estimates for the year 2000 and projections for 2030. Diabetes Care 2004;27:2568-9.

4. Ginsberg HN, Elam MB, Lovato LC, ACCORD Study Group. Effects of combination lipid therapy in type 2 diabetes mellitus. N Engl J Med 2010;362:1563-74

5. Tumosa N. Eye disease and the older diabetic. Clin Geriatr Med 2008;24:515-27.

6. World Health Organization. Prevention of Blindness from Diabetes Mellitus. Geneva: WHO; 2006

7. Dandona L, Dandona R, Naduvilath TJ, McCarty CA, Rao GN. Population-based assessment of diabetic retinopathy in an urban population in Southern India. Br J Ophthalmol 1999;83:937-40

8. Rema M, Deepa R, Mohan V. Prevalence of retinopathy at diagnosis among type 2 diabetic patients attending a diabetic center in South India. Br J Ophthalmol 2000;84:1058-60

9. Rema M, Premkumar S, Anitha B, Deepa R, Pradeepa R, Mohan $\mathrm{V}$ et al. Prevalence of diabetic retinopathy in urban India: The Chennai Urban Rural Epidemiology Study (CURES) eye study, I. Invest Ophthalmol Vis Sci 2005;46:2328-33

10. Raman R, Rani PK, Reddi Rachepalle S, Gnanamoorthy P, Uthra S, Kumaramanickavel G, et al. Prevalence of diabetic retinopathy in India: Sankara Nethralaya diabetic retinopathy epidemiology and molecular genetics study report 2 . Ophthalmol 2009;116:311-8.

11. Namperumalsamy P, Kim R, Vignesh TP, Nithya N, Royes J, Gijo T, et al. Prevalence and risk factors for diabetic retinopathy: A population-based assessment from Theni district, South India. Br J Ophthalmol 2009;93:429-34.

12. Jonas JB, Nangia V, Khare A, Matin A, Bhojwani K, Kulkarni $\mathrm{M}$, et al. Prevalence and associated factors of diabetic retinopathy in rural central India. Diabetes Care 2013;36:e69.

13. Shera AS, Jawad F, Maqsood A, Jamal S, Azfar M, Ahmed U et al. Prevalence of chronic complications and associated factors in type 2 diabetes. J Pak Med Assoc 2004;54:54-9.
14. Ahmed RA, Khalil SN, Al-Qahtani MA. Diabetic retinopathy and the associated risk factors in diabetes type 2 patients in Abha, Saudi Arabia. J Family Community Med 2016;23:18-24.

15. WHO. Prevention of blindness from diabetes mellitus. Report of a WHO consultation in Geneva, Switzerland, 9-11 November 2005. Geneva: World Health Organization.

16. WHO. The conference report on VISION 2020 Planning for Eastern Mediterranean Region Report no. WHO/EMR/PBL/03.1, December 2003. Cairo: World Health Organization.

17. Rani P, Raman R, Chandrakantan A, et al. Risk factors for diabetic retinopathy in a self-reported rural population with diabetes. J Postgrad Med 2009;55:92-6.

18. Huang OS, Zheng Y, Tay WT. Lack of awareness of common eye conditions in the community. Ophthalmic Epidemiol 2013;20:52-60.

19. 19.Geethadevi M, Thampi B, Antony J, Raghavan R, Sashidharan RR, Mohan A et al. A study of knowledge, attitude, and practice in diabetic retinopathy among patients attending a primary health center. Int J Res Med Sci 2018;6:3020-4

20. 20.Hussain R, Rajesh B, Giridhar A, Gopalakrishnan M, Sadasivan S, James J, et al. Knowledge and awareness about diabetes Mellitus and diabetic retinopathy in a suburban population of a South Indian state and its practice among the patients with diabetes mellitus.A population-based study. Indian J Ophthalmol 2016;64:272-6.

21. Raghu V, Shruthi T, Saidivya R, Rohini M. To evaluate the awareness of diabetic retinopathy in self-reported diabetic patients attending tertiary care center in rural Telangana. MRIMS J Health Sci 2016;4(2):85-8.

22. Namperumalsamy P, Nirmalan PK, Ramasamy K. Developing a screening program to detect sight-threatening diabetic retinopathy in South India. Diabetes Care 2003;26:1831-5

How to cite this article: Chowdhury RK, Dora J, Priyadarshini K. Awareness and knowledge of Diabetic retinopathy among Diabetic patients in a tertiary care hospital of western Odisha, India. Indian J Clin Exp Ophthalmol. 2019;5(3):292-6. 